Graphic Abstract:

Composition and Acidity Tuned Spatially by ALD on Unit-cell Thick 2D Zeolite Nanosheets in Pillared Layered Zeolites

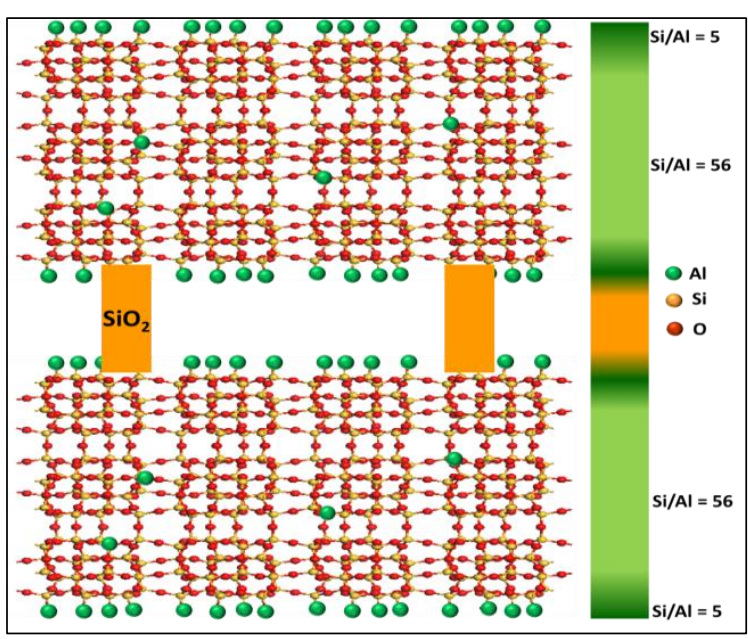

ALD-Al of PMFI

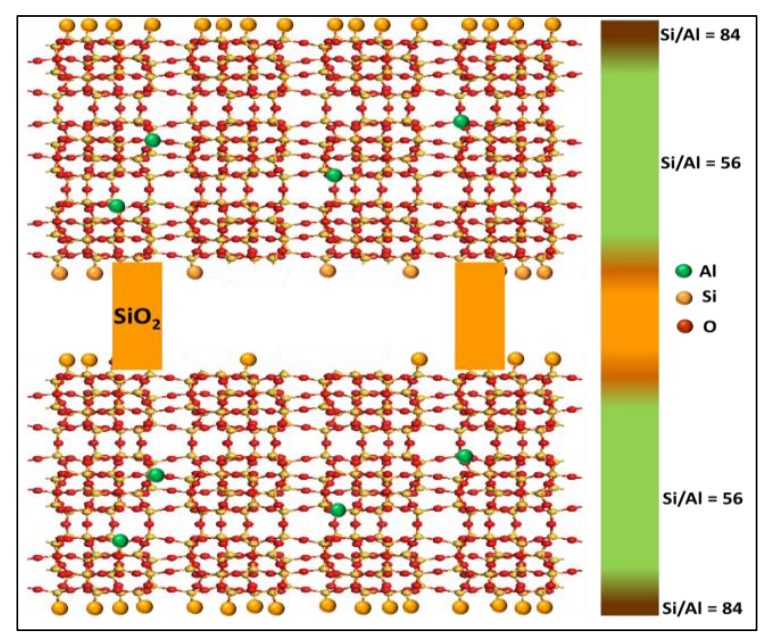

ALD-Si of PMFI

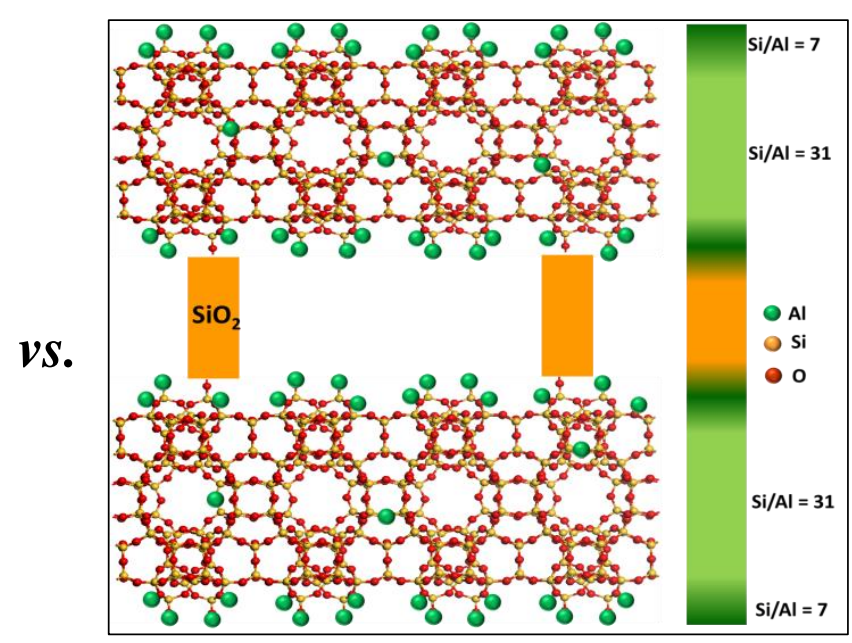

ALD-Al of PMWW

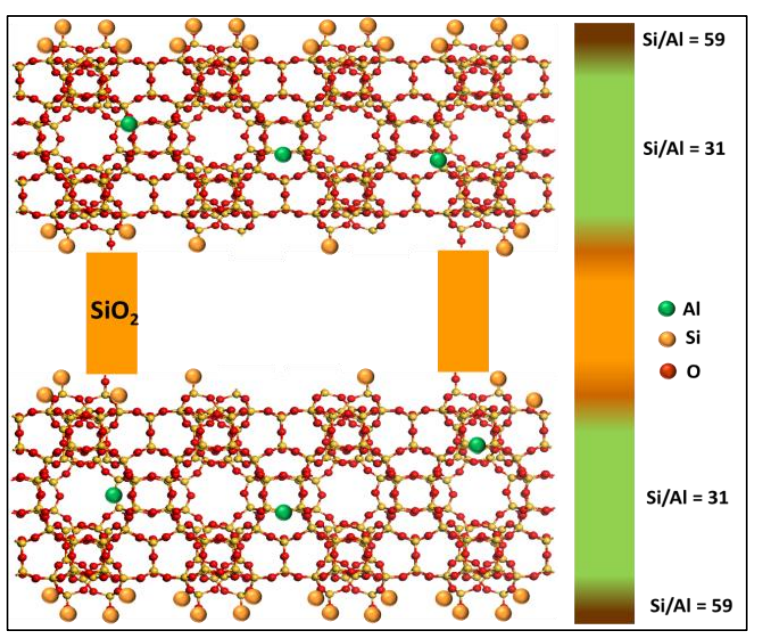

ALD-Si of PMWW 


\section{Tuning External Surface of Unit-Cell Thick Pillared MFI and MWW Zeolites by Atomic Layer Deposition and Its Consequences on Acid-Catalyzed Reactions}

Yiqing $\mathrm{Wu}^{1}$, Zheng $\mathrm{Lu}^{2}$, Laleh Emdadi ${ }^{1}$, Su Cheun $\mathrm{Oh}^{1}$, Jing Wang ${ }^{3}$, Yu Lei ${ }^{2}$, Huiyong $\mathrm{Chen}^{3}$, Dat T. Tran ${ }^{4}$, Ivan C. Lee ${ }^{4}$ and Dongxia Liu ${ }^{*}$

1. Department of Chemical and Biomolecular Engineering, University of Maryland, College Park, MD, 20742, USA

2. Department of Chemical and Materials Engineering, University of Alabama, Huntsville, AL 35899, USA

3. School of Chemical Engineering, Northwest University, Xi'an, Shaanxi, 710069, China

4. U.S. Army Research Laboratory, RDRL-SED-E, 2800 Powder Mill Road, Adelphi, MD, 20783, USA

*Corresponding author:

Prof. Dongxia Liu

Email: liud@umd.edu

Phone: (+1) 301-405-3522

Fax: (+1) 301-405-0523 
Abstract: The pillared MWW (PMWW or MCM-36) and pillared MFI (PMFI) zeolites are 2dimensional (2D) catalytically active materials made by pillaring of layered MCM-22(P) and multilamellar MFI precursors, respectively. The single- or near single-unit-cell thick 2D microporous layers in PMWW and PMFI expose comparable number of external surface acid sites (i.e., acid sites enclosed in mesopores between zeolitic layers) to those in micropores, which become important or dominant contributor to the catalytic properties. Although the acidity and catalytic activities of PMWW and PMFI have been studied, modification of their external surfaces and its implications on catalytic reactions are not available. In the present study, we report the tailoring of external surfaces of PMWW and PMFI zeolites by atomic layer deposition (ALD) of silicon (ALD-Si) and aluminum (ALD-Al), respectively. The textural, acidic and catalytic properties of the ALD modified pillared zeolites were investigated using a variety of characterization methods. ALD-Al and ALD-Si modifications kept micropore almost intact, but resulted in significant reduction in mesopore volume and considerable changes in external surface composition and acidity. The catalytic tests showed that intrinsic catalytic behavior of Brønsted acid sites in ALD modified pillared zeolites was similar to their parent counterparts. In diffusion constrained parallel reactions, ALD of Al- or Si-species altered catalyst selectivity. In addition, ALD of Si-species on PMFI zeolite deactivated surface active sites, which resulted in improved catalytic activity in direct methane aromatization reactions under optimal ALD cycles. The study exemplified for the first time that ALD is an effective tool for tuning the surface properties of 2D unit-cell thick zeolites.

Keywords: Unit-cell thick zeolite; Hierarchical zeolite; Acidity; Atomic layer deposition (ALD); Brønsted acid sites; Methane aromatization. 


\section{Introduction}

Zeolites are widely used as heterogeneous catalysts in petrochemical and fine chemical synthesis, mainly due to their well-defined structure, composition and angstrom-size micropores [1-5]. The processing of bulky molecules in zeolites, however, has been restricted by limited access and slow transport to/from the active sites, which renders low catalyst utilization [6-8]. Lamellar zeolites, or in more general case, two-dimensional (2D) zeolites create opportunities to develop zeolites with open structures and surface exposed active sites for overcoming the active site accessibility and mass-transport limitations [9-11]. The 2D zeolite precursors contain stacked sheets of one-to-two unit cell or smaller thickness organized by weak forces through the interactions of organic/inorganic ions and/or molecules located in the "interlayer" spaces. Structural modifications such as intercalation [12-16], exfoliation [17-21], pillaring [22, 23], etc. of the 2D zeolite precursors can synthesize pillared, delaminated and disordered zeolites with single- or near single-unit-cell thick open structures. A themed issue on layered inorganic materials in Dalton Transactions has summarized the state-of-the-art synthesis, characterization, and properties of 2D zeolite materials [24-27].

Although the synthesis, textural properties and potential applications of the unit-cell thick 2D zeolites have been well studied in recent literature [9-11, 27-29], evaluations of catalytic behaviors of active sites on external surfaces (external active sites) of $2 \mathrm{D}$ zeolites are rarely available. As the characteristic length of the microporous domains in 2D zeolites stays at the single- or near single-unit-cell level, the fraction of external active sites becomes comparable to that in micropores, and consequently, the catalytic properties of the former becomes important or dominant contributor to the overall catalyst performances. Studies on catalytic behaviors of external acid sites, and furthermore, modifications of external surface structures of 2D zeolites 
will assist fundamental understanding and create new structural and functional properties of these materials.

Atomic layer deposition (ALD) has emerged as an attractive elegant method for atomic level design and synthesis of catalyst materials [30-32]. It involves a synthesis process using alternating, self-limiting reactions between gaseous precursors and a solid surface to deposit materials in an atomic layer-by-layer fashion. The self-limiting character of the reactions makes it possible to achieve uniform deposits on high-surface-area porous solid materials. ALD has been used to control the porosity and surface properties of mesoporous catalytic materials [3336], to synthesize zeolite materials [37], as well as to load metal or metal oxide onto zeolite materials [38-40]. Application of ALD to nanoporous zeolites is a new area and is presumably more complicated compared to above applications because of the subtle differences in diameters between the ALD reactant molecules and the zeolite pore apertures. Previous attempt to conduct ALD of aluminum (ALD-Al) into silicalite-1 zeolite, the MFI framework with 10 membered ring (10-MR), was not successful [41]. It was ascribed to the small pore size of silicalite-1, which is too narrow to adsorb trimethylaluminium (TMA) precursor molecules used in ALD-Al process.

In the present work, we report to employ the ALD technique to tune the surface properties of unit-cell thick $2 \mathrm{D}$ zeolite catalyst materials in order to tailor their catalytic properties. Pillared MWW (or MCM-36) and pillared MFI zeolites were used as unit-cell thick 2D zeolites in this study. MCM-36 is the first synthesized pillared 2D zeolite, which is derived from a layered precursor, MCM-22(P), reported by Mobil scientists in 1990's [42, 43]. Pillared MFI was reported by Ryoo and co-workers [29], which is synthesized by silica pillaring of the multilamellar MFI that is created by a diquaternary ammonium surfactant $\left(\mathrm{C}_{22} \mathrm{H}_{45}-\mathrm{N}^{+}\left(\mathrm{CH}_{3}\right)_{2}-\right.$ $\left.\mathrm{C}_{6} \mathrm{H}_{12}-\mathrm{N}^{+}\left(\mathrm{CH}_{3}\right)_{2}-\mathrm{C}_{6} \mathrm{H}_{13}\left(\mathrm{Br}^{-}\right)_{2}\right)$ assisted hydrothermal crystallization process [29]. ALD of silicon 
(Al-Si) and ALD-Al were conducted to tune the porosity and surface acidity of pillared MFI and pillared MWW zeolites. The physicochemical and acidic properties of the resultant ALDmodified 2D zeolites were investigated using a variety of characterization techniques. The catalytic properties were explored by ethanol dehydration reaction, alkylation and etherification of benzyl alcohol in mesitylene, and direct methane aromatization (DMA) reactions, respectively. Ethanol dehydration reaction was used to probe intrinsic catalytic consequences of Brønsted acid sites in ALD-modified 2D zeolite catalysts. Alkylation and etherification of benzyl alcohol in mesitylene were used to evaluate the catalytic activity and selectivity of external acid sites in these catalysts. DMA reactions were carried out to evaluate the overall performance of the catalysts when the external acid sites were passivated by ALD-Si modifications. For simplicity in nomenclature, pillared MWW and pillared MFI are designated as PMWW and PMFI, respectively, in the remainder of this paper.

\section{Experimental}

2.1 Preparation of zeolite catalysts

2.1.1 Synthesis of PMWW and PMFI Zeolites. PMWW zeolite was derived from the precursor, MCM-22(P). The hydrothermal synthesis of MCM-22(P) was carried out by using the method described by Corma et al. [21] The MCM-22(P) was swollen according to the method developed by Maheshwari et al. [23], followed by pillaring of the swollen material using the procedure reported by Barth et al. [44] to make PMWW zeolite. PMFI was made by following the method reported by Na et al. [22] using a multilamellar MFI precursor. The multilamellar MFI was synthesized using the method reported by Ryoo and co-workers [29]. The as- 
synthesized PMFI and PMWW zeolites were ion-exchanged three times using $1 \mathrm{M}$ aqueous ammonium nitrate $\left(\mathrm{NH}_{4} \mathrm{NO}_{3}\right)$ (weight ratio of zeolite to $\mathrm{NH}_{4} \mathrm{NO}_{3}$ solution $=1: 10$ ) at $353 \mathrm{~K}$ for $12 \mathrm{~h}$, and subsequently, collected by vacuum filtration, washed with deionized (DI) water three times, and dried at $343 \mathrm{~K}$ overnight. All zeolite samples in their $\mathrm{NH}_{4}{ }^{+}$-form were treated in dry air (100 $\mathrm{mL} \mathrm{min}^{-1}$, Airgas) by increasing the temperature from ambient temperature to $823 \mathrm{~K}$ at $0.03 \mathrm{~K} \mathrm{~s}^{-1}$ and holding for $4 \mathrm{~h}$ to thermally decompose $\mathrm{NH}_{4}^{+}$to $\mathrm{NH}_{3}$ and $\mathrm{H}^{+}$.

2.1.2. ALD modification of PMWW and PMFI zeolites. The ALD-Si and ALD-Al were performed in a viscous flow benchtop reactor (Gemstar-6, Arradiance). $\mathrm{N}_{2}$ (Airgas, 99.999\% purity) was used as a carrier gas $\left(50 \mathrm{~mL} \mathrm{~min}^{-1}\right)$ and further purified by a Supelco gas purifier (Sigma-Aldrich) before entering the reactor. $0.5 \mathrm{~g}$ of zeolite (PMWW or PMFI) was uniformly spread onto a stainless steel tray with a mesh on top of it. The mesh prevented the spill of the sample and allowed access to the $\mathrm{Si}$ - or $\mathrm{Al}$ - precursor vapor in the ALD process. The ALD-Si was carried out by alternative exposure of zeolite sample to tris(dimethylamino)silane (TDMAS, Sigma-Aldrich, 99.999\%) and ozone at $573 \mathrm{~K}$ for $15 \mathrm{~s}$, followed by $\mathrm{N}_{2}$ purge for $200 \mathrm{~s}$ after each exposure. The ALD-Al was conducted by exposing the zeolite sample to TMA (Sigma-Aldrich, 97\%) for $15 \mathrm{~s}$, purging with $\mathrm{N}_{2}$ for $100 \mathrm{~s}$, exposing the sample to DI water for $22.5 \mathrm{~s}$, and purging with $\mathrm{N}_{2}$ for $100 \mathrm{~s}$ again. The zeolite sample temperature was kept at $473 \mathrm{~K}$ in the ALDAl preparation process. One ALD cycle was used for either Si or Al modification of PMWW and PMFI zeolites, unless specially specified in the paper. The resultant zeolite samples from ALDSi and ALD-Al modifications were denoted as Si-PMWW and Si-PMFI, or Al-PMWW and AlPMFI, respectively.

2.1.3. Preparation of Mo/zeolite catalysts for DMA reactions. The wetness impregnation method was used to prepare the $2 \mathrm{wt} \%$ molybdenum/zeolite (Mo/zeolite) catalysts for DMA 
reactions. Typically, $0.0378 \mathrm{~g}$ of ammonium molybdenum tetrahydrate (99\% purity, SigmaAldrich) was dissolved in $0.5 \mathrm{~g}$ DI water at room temperature to form a solution, which was then added dropwise to $1 \mathrm{~g}$ of Si-PMFI zeolite sample. The as-prepared Mo/Si-PMFI catalyst was dried at $393 \mathrm{~K}$ overnight, followed by a two-stage calcination procedure reported in our previous work $[45,46]$. In the first stage, the sample was heated from room temperature to $623 \mathrm{~K}$ at 0.017 $\mathrm{K} \mathrm{s}^{-1}$ in flowing air $\left(100 \mathrm{~mL} \mathrm{~min}^{-1}\right)$ and soaked at this temperature for $16 \mathrm{~h}$. For the subsequent stage, the sample was heated to $973 \mathrm{~K}$ at $0.017 \mathrm{~K} \mathrm{~s}^{-1}$ and soaked at this temperature for $10 \mathrm{~h}$. The resultant Mo/zeolite catalyst was pelletized, crushed, and sieved to retain the particle sizes between 180 and $425 \mu \mathrm{m}$ (40-80 mesh) for subsequent DMA reactions.

\subsection{Characterization of zeolite catalysts}

2.2.1. Textural property and composition analysis. The morphologies of the 2D PMWW and PMFI zeolite samples, before and after ALD treatments, respectively, were observed using scanning electron microscopy (SEM, Hitachi SU-70). $\mathrm{N}_{2}$ adsorption-desorption isotherms were measured at $77 \mathrm{~K}$ with an Autosorb-iQ analyzer (Quantachrome Instruments) to characterize the textural properties of the zeolite samples. Prior to the measurement, all the zeolites were evacuated overnight at $623 \mathrm{~K}$ and $1 \mathrm{~mm} \mathrm{Hg}$. Elemental compositions of the samples were determined by inductively coupled plasma optical emission spectroscopy (ICP-OES, Perkin Elmer Optima 7000). ${ }^{27} \mathrm{Al}$ magic-angle spinning (MAS) nuclear magnetic resonance (NMR) spectra were used to examine the bonding environment of Al sites in the zeolite catalysts. The NMR spectra were recorded at $130.34 \mathrm{MHz}$ using $4 \mathrm{~mm}$ rotors at $14 \mathrm{kHz}$ spinning speed, a dwell time of $0.5 \mu \mathrm{s}$, a selective $\pi / 18$ pulse of $0.3 \mu$ s and a recycle delay of $0.1 \mathrm{~s}$. An aqueous solution of aluminum sulfate $(0.1 \mathrm{M})$ was used as the external reference $(0 \mathrm{ppm})$. The surface $\mathrm{Si}$ and $\mathrm{Al}$ 
concentrations were quantified using a X-ray photon spectrometer (Kratos AXIS 165) equipped with $165 \mathrm{~mm}$ radius hemispherical analyzer and eight channeltron detection system coupled with monochromatic $\mathrm{Al}$ radiation $(1486.6 \mathrm{eV})$.

2.2.2. Acidity determination. The Fourier transform infrared (FTIR) spectra of adsorbed pyridine were used to determine the type and concentration of Brønsted and Lewis acid sites in the catalysts. The spectra were recorded using a spectrophotometer (Equinox 55, Bruker) equipped with a Spectra-Tech Collector II diffuse reflectance accessory and a Praying Mantis high temperature reaction chamber (Harrick). Prior to the measurement, the zeolite sample was dried at $823 \mathrm{~K}$ under He flow $\left(50 \mathrm{~mL} \mathrm{~min}{ }^{-1}\right)$ for $1 \mathrm{~h}$. After cooling the sample to $393 \mathrm{~K}$, adsorption of pyridine was performed by flowing a mixed pyridine and He gas stream through the catalyst. Following adsorption, the sample was heated to $523 \mathrm{~K}$ under a flowing He to desorb the physisorbed pyridine, cooled to the temperature of $393 \mathrm{~K}$, and then FTIR spectra were recorded in the range of $4000-400 \mathrm{~cm}^{-1}$ with 128 scans at an effective resolution of $2 \mathrm{~cm}^{-1}$.

The number of free Brønsted acid sites in the catalyst samples were measured via dimethyl ether (DME) titration experiments given that the Brønsted acid sites participate in reactions of DME with $\mathrm{H}^{+}$to form surface methyl groups, $\mathrm{CH}_{3} \mathrm{OCH}_{3}+2[\mathrm{SiO}(\mathrm{H}) \mathrm{Al}]=$ $2\left[\mathrm{SiO}\left(\mathrm{CH}_{3}\right) \mathrm{Al}\right]+\mathrm{H}_{2} \mathrm{O}[47,48]$. The experiments were carried out in a tubular packed-bed quartz reactor $(10 \mathrm{~mm}$ inner diameter) under atmospheric pressure. The temperature of the reactor was held constant by a resistively heated furnace (National Electric Furnace FA120 type) where the temperature was controlled by a Watlow Controller (96 series). Catalyst temperatures were measured using a K-type thermocouple touching the bottom of a well on the external surface of the quartz reactor. Details on the DME titration experimental setup and reaction conditions were described 
in our previous publications $[45,46]$. The same setup was used for the following organic base titration and gas-phase catalytic reaction studies.

2.2.3. External free acid site determination. To study the spatial distribution of external Brønsted acid sites (i.e., acid sites stay nearby micropore mouth or on the external surface of 2D zeolite samples, which was defined as the external acid sites), methanol $\left(\mathrm{CH}_{3} \mathrm{OH}\right)$ dehydration to DME in the presence of 2,6-di-tert butylpyridine (DTBP) organic base was measured at differential conversions (<2\%) at $433 \mathrm{~K}$. Liquid mixture of methanol (Fisher Scientific, 99.9\%) and DTBP (Alfa, 98\% purity) was introduced into a flowing He stream using a syringe pump (NE 1000, New Era Pump System Inc.). The reactor effluent was sent via heated transfer lines to a mass spectrometer (MS, Ametek Proline). The methanol dehydration rate was measured as DTBP titrant was continuously added until it reached a plateau. The loss in methanol reaction rate reflects the degree of accessibility of bulky DTBP molecules to Brønsted acid sites in zeolites, and hence, the number of active sites accessible from the external surface of pillared zeolites was determined. The fraction of external acid sites, $\mathrm{f}_{\mathrm{ext}, \mathrm{H}^{+}}$, was calculated as the ratio of the external acid sites to the acid sites quantified by the DME titration. Details on method for external acid site determination can be referred to our previous work [45].

\subsection{Acid-catalyzed reactions over ALD-modified 2D zeolite catalysts}

2.3.1. Ethanol dehydration reaction. Ethanol dehydration was used as the probe reaction to determine the intrinsic activity of Brønsted acid sites in the zeolite catalysts. Typically $0.05 \mathrm{~g}$ catalyst was pre-treated in He flow $\left(30 \mathrm{~mL} \mathrm{~min}^{-1}\right.$, UHP grade, Airgas) at $823 \mathrm{~K}$ for $3 \mathrm{~h}\left(0.03 \mathrm{~K} \mathrm{~s}^{-}\right.$ ${ }^{1}$ ) prior to cooling down to reaction temperature in He flow. Steady-state ethanol reaction with differential conversion $(<2 \%)$ was carried out under atmospheric pressure and in a reaction 
temperature range of 393-423 K. Liquid ethanol was injected by the syringe pump and vaporized at $353 \mathrm{~K}$ into a He carrier flow $\left(48 \mathrm{~mL} \mathrm{~min}^{-1}\right)$ with $\mathrm{Ar}\left(2 \mathrm{~mL} \mathrm{~min}{ }^{-1}\right)$ as inner standard. The transfer line was heated over $353 \mathrm{~K}$ by resistively heating tape to avoid the condensation of ethanol. The unreacted ethanol, diethyl ether (DEE, reaction product) and Ar were recorded to calculate the reaction rate by a gas chromatograph (Agilent 7890 A GC) equipped with a methylsiloxane capillary column $(\mathrm{HP}-1,50.0 \mathrm{~m} \times 320 \mu \mathrm{m} \times 0.52 \mu \mathrm{m})$ connected to a flame ionization detector (FID) and a packed column (ShinCarbon ST Columns, 80/100 mesh, 6 feet) connected to a thermal conductivity detector (TCD).

2.3.2. Catalytic conversion of Benzyl alcohol in Mesitylene. The liquid phase catalytic conversion of benzyl alcohol in mesitylene was carried out in a three-necked round-bottom flask $(100 \mathrm{~mL})$ under atmospheric pressure and magnetic stirring, as reported in our previous work [49]. In a typical experiment, $15 \mathrm{~mL}$ of mesitylene was added to the desired amount of zeolite catalyst, which was maintained for $0.5 \mathrm{~h}$ at the required reaction temperature and stirring conditions and then $0.25 \mathrm{~mL}$ of benzyl alcohol was added. The moment of addition of benzyl alcohol was taken as the initial reaction time. Liquid samples were withdrawn at regular time intervals and analyzed by the gas chromatograph described above.

2.3.3. Direct methane aromatization reactions. The DMA reactions were conducted by heating $2 \mathrm{wt} \% \mathrm{Mo} / \mathrm{Si}-\mathrm{PMFI}$ catalyst $(\sim 0.30 \mathrm{~g})$ from ambient temperature in He flow $(30 \mathrm{~mL}$ $\min ^{-1}$ ) to $950 \mathrm{~K}$ at ramp rate $0.167 \mathrm{~K} \mathrm{~s}^{-1}$ under atmospheric pressure. After temperature of catalysts reached $950 \mathrm{~K}$, the DMA reactions were carried out by introducing methane into the catalyst at a flow rate of $8.0 \mathrm{~mL} \mathrm{~min}^{-1}$ and Ar of $2.0 \mathrm{~mL} \mathrm{~min}^{-1}$ as internal standard. The transfer lines were maintained at temperatures greater than $473 \mathrm{~K}$ by resistive heating to prevent product 
condensation. The effluents from the reaction were analyzed using the gas chromatograph described above.

\section{Results and discussion}

3.1. Textural properties of ALD-modified pillared zeolite catalysts

SEM observation was conducted for direct visualization of zeolite morphologies before and after ALD-Si or ALD-Al onto the pillared 2D zeolite samples. The PMWW sample (Figure 1(A)) contains flake-like particles with length of $0.5-1 \mu \mathrm{m}$ and thickness of $50-100 \mathrm{~nm}$. SiPMWW and Al-PMWW samples resemble the flake-like morphology of PMWW zeolite, as evidenced in Figure 1(B) and (C), respectively. The similarity in morphologies of these three samples indicates that one cycle of ALD-Si or ALD-Al did not considerably alter the morphologies of 2D PMWW zeolite. The PMFI (Figure 1(D)) is comprised of intertwined platelet-like particles with widely distributed sizes, similar to pillared MFI reported by Na et al. [29]. Figure 1(E) and (F) show that Si-PMFI and Al-PMFI have similar morphologies to that of PMFI, further confirming that no obvious morphology alteration occurred on the PMFI sample in the one cycle ALD process.

$\mathrm{N}_{2}$ adsorption-desorption isotherms and pore size distributions extracted from adsorption branch of isotherms were used to reveal the textural property changes in PMWW and PMFI zeolites after ALD-Si or ALD-Al modifications. Figure 2(A) shows that the PMWW, Si-PMWW and Al-PMWW samples have slightly different sorption behavior up to a relative pressure $p / p_{0} \sim 0.05$ and distinct sorption capacities when $p / p_{0}$ is higher than 0.1 . The majority of the sorption results from zeolite micropores when the relative pressure is below $p / p_{0} \sim 0.05$ [50], indicating that ALD treatment only mildly altered the micropore volume of the PMWW zeolite 
(Figure 2(B)). The $\mathrm{N}_{2}$ uptake at higher relative pressures is ascribed to capillary condensation in mesopores of pillared zeolite materials [50]. The sequential decrease in sorption capacity from PMWW, Si-PMWW to Al-PMWW suggests ALD treatment significantly decreased the mesopore volume of PMWW zeolite, and ALD-Al caused more obvious reduction in mesopore volume than that of ALD-Si. The mesoporosity change indicates that ALD-Al process deposited more materials than ALD-Si on the PMWW zeolite. The reduction in mesopore volume is also evidenced by the non-local density functional theory (NLDFT) pore size distributions of these three materials in Figure 2(C). It should be noted that the average mesopore sizes of PMWW, SiPMWW and Al-PMWW are similar. The present analysis demonstrates that ALD modification of PMWW decreased the mesopore volume while keeping the mesopore size almost intact.

Figure 2(D)-(F) show the $\mathrm{N}_{2}$ adsorption-desorption isotherms of PMFI, Si-PMFI and AlPMFI, and their corresponding pore size distributions. Similar to the textural property changes in PMWW-type zeolites, PMFI, Si-PMFI and Al-PMFI have similar sorption capacity at relatively low pressures $\left(p / p_{0}<0.1\right)$, which suggests that they all have similar microporosity (Figure 2(E)). The mesopore volume, indicated by sorption capacity at higher relative pressures $\left(p / p_{0}=0.1-0.5\right)$, follows the order of Al-PMFI < Si-PMFI < PMFI (Figure 2(F)). Different from PMWW-type zeolite, the ALD treatment of PMFI zeolite led to constant micropore volume, reduction in mesopore volume and decrease in mesopore size. As shown in Figure 2(F), the average mesopore size shifted from $3.5 \mathrm{~nm}, 3.3 \mathrm{~nm}$ to $3.0 \mathrm{~nm}$ from PMFI, Si-PMFI to Al-PMFI zeolites.

PMWW is a silica pillared layered 2D zeolite material, derived from the precursor MCM22 (P) $[42,43]$. The PMWW structure possesses independent micropore and mesopore systems within the layers and between the layers, respectively. Within the layers, PMWW contains 2D sinusoidal 10 MR channels (diameters 4.1 x $5.1 \AA$ A) running parallel to the layer's basal plane. 
Perpendicular to the layers, PMWW contains hourglass shaped pores with 12 MR openings (with dimensions of $7.1 \times 9.1 \AA$ ) at the entrance and 6 MR channels at the central constrictions [51, 52]. PMFI zeolite is also a silica pillared 2D zeolite material, consisting of two interconnected $10 \mathrm{MR}$ pore systems within each layer: one is a straight channel running along the $b$-axis direction $(5.3 \times$ $5.6 \AA)$; and the other is a zigzag channel running parallel to the $a$-axis $(5.1 \times 5.5 \AA)$. The PMFI contains mesopores created by the silica pillars running between layers, parallel to the zigzag channels and perpendicular to the straight channel within the layers $[8,22]$. The almost intact micropore volume in PMFI after ALD modifications is consistent with previous report that ALD-Al of silicalite-1 using TMA precursor was unsuccessful due to the small 10-MR pore aperture [41]. The slight decrease in micropore volume in PMWW after ALD treatment was caused by deposition of Si- or Al-species in the 12-MR cups in the MWW zeolitic layer, similar to ALD of FAU zeolite that has 12-MR micropores [41, 53]. The higher mesopore volume loss upon ALD-Al compared to ALD-Si resulted from the smaller molecular size of Al-species precursor (TMA) compared to Si-species precursor (TDMAS), since the former has less diffusion limitation when marched on the zeolite nanosheets in the ALD process. The persistence and decrease in average mesopore sizes in PMWW and PMFI, respectively, in ALD processes might be relevant to the different micro- and mesopore topologies and the consequent different dynamic behaviors of Al- or Si-precursor molecules in the zeolites during diffusion and deposition processes.

\subsection{Composition of ALD-modified pillared zeolite catalysts}

The compositions of PMWW and PMFI zeolites and their derivatives after ALD modifications were measured by ICP-OES analysis, and the results (represented by $\mathrm{Si} / \mathrm{Al}$ ratios) 
are shown in Table 1. For both PMWW and PMFI zeolites, the ALD-Al resulted in a decrease in $\mathrm{Si} / \mathrm{Al}$ ratios, while $\mathrm{ALD}-\mathrm{Si}$ caused an opposite trend in changes of $\mathrm{Si} / \mathrm{Al}$ ratios. The amount of Si- or Al-species deposited on the PMWW and PMFI zeolite samples can be calculated from the changes in their $\mathrm{Si} / \mathrm{Al}$ ratios after ALD processes. The calculation indicates that ALD-Si led to $1.7 \mathrm{wt} \%$ and $3.8 \mathrm{wt} \%$ weight gains in Si-PMFI and Si-PMWW, respectively. The ALD-Al process, however, led to $11.0 \mathrm{wt} \%$ and $9.8 \mathrm{wt} \%$ weight increases in PMFI and PMWW, respectively, much higher than those in ALD-Si process. The TDMAS precursor used in ALD-Si is bulkier than TMA precursor in ALD-Al, which mainly contributes to the differences in zeolite weight gains in both ALD processes, since the former has more severe steric hindrances when diffusing through the mesopores of pillared zeolites. The difference in topological structures of PMFI and PMWW zeolites also affects deposition of Si-species in ALD-Si process, as evidenced by $>2$ times higher amount of Si-species deposited on Si-PMWW than Si-PMFI.

The surface compositions of PMWW and PMFI zeolites before and after ALD treatments were evaluated by XPS analysis. The $\mathrm{Si} / \mathrm{Al}$ ratio, calculated from atomic percentages quantified by XPS signals, increased from 50 to 59, and decreased to 7 for PMWW, Si-PMWW and AlPMWW zeolites in sequence. Similar changes in $\mathrm{Si} / \mathrm{Al}$ ratio were observed for $\mathrm{PMFI}(\mathrm{Si} / \mathrm{Al}=$ 68), Si-PMFI ( $\mathrm{Si} / \mathrm{Al}=84)$ and Al-PMFI $(\mathrm{Si} / \mathrm{Al}=5)$ zeolite samples (Table 1$)$. If we make an assumption that the entire zeolite particle has the same composition as that of the external surface determined by XPS in Table 1, the Si- or Al-species deposited on the exterior of PMWW and PMFI zeolite particles can be estimated. From such analysis, the weight increases on the exterior of the Si-PMFI, Si-PMWW, Al-PMFI and Al-PMWW particles are estimated to be 18.8 $\mathrm{wt} \%, 15.0 \mathrm{wt} \%, 13.4 \mathrm{wt} \%$ and $9.3 \mathrm{wt} \%$, respectively. The significant higher weight gains on the exterior than that of the entire zeolite particles in ALD-Si process indicate that Si-species mainly 
resides on the geometrical surfaces of the PMWFI and PMWW zeolite samples. The weight gains on the exterior and the entire particles in the ALD-Al process, however, are similar, suggesting that Al-species distributes uniformly on geometrical surfaces of zeolite particles and in mesopore (i.e., external surface of unit-cell thick zeolite nanosheets) of the Al-PMFI and AlPMWW samples. The mesopore gallery between two unit-cell thick zeolititic nanosheets, parallel to the width of PMWW flakes and PMFI platelets, might be big enough to allow TMA to transport through but resist TDMAS diffusion, and as a result, led to more $\mathrm{Si}$-species deposited on the exterior of the zeolite particles. This analysis suggests that the spatial composition (exterior - mesopore (or external surface) - micropore) of 2D pillared zeolites is different, which is easily realized and tailored by the ALD of Si- or Al-precursor molecules with variant sizes.

\subsection{Acidity of ALD-modified pillared zeolite catalysts}

To determine the number of active Brønsted acid sites $\left(N_{\text {total, } \mathrm{H}^{+}}\right)$in Si-PMFI, Al-PMFI, Si-PMWW and Al-PMWW samples, DME titrations, with reactions of DME with Brønsted acid sites $\left(\mathrm{H}^{+}\right)$to form surface methyl groups, $\mathrm{CH}_{3} \mathrm{OCH}_{3}+2[\mathrm{SiO}(\mathrm{H}) \mathrm{Al}]=2\left[\mathrm{SiO}\left(\mathrm{CH}_{3}\right) \mathrm{Al}\right]+\mathrm{H}_{2} \mathrm{O}[47$, 48], were conducted. The concentration of Brønsted acid sites changed from $1.85 \times 10^{-4} \mathrm{~mol} \mathrm{H}^{+} \mathrm{g}^{-}$ ${ }^{1}$ to $1.26 \times 10^{-4} \mathrm{~mol} \mathrm{H}^{+} \mathrm{g}^{-1}$ and from $3.30 \times 10^{-4} \mathrm{~mol} \mathrm{H}^{+} \mathrm{g}^{-1}$ to $2.39 \times 10^{-4} \mathrm{~mol} \mathrm{H}^{+} \mathrm{g}^{-1}$, respectively, when ALD-Si was applied to PMFI and PMWW zeolites (Table 1). The decreases in number of active Brønsted acid sites in Si-PMFI (by 32\%) and Si-PMWW (by 28\%) can be ascribed to the concealment of external acid sites by the deposited Si-species. The ALD-Al modifications, however, increased the number of active Brønsted acid sites to $4.19 \times 10^{-4} \mathrm{~mol} \mathrm{H}^{+} \mathrm{g}^{-1}$ and 3.66 $\mathrm{x} 10^{-4} \mathrm{~mol} \mathrm{H}^{+} \mathrm{g}^{-1}$ in Al-PMFI and Al-PMWW, respectively (Table 1). The emergence of new acid sites in Al-PMFI (by 126\%) and Al-PMWW (by 11\%) via ALD-Al processes might be due to the 
bridging hydroxyls $(\mathrm{Si}-\mathrm{O}(\mathrm{H})-\mathrm{Al})$ on pillared zeolites bonded to distorted $\mathrm{Al}$ tetrahedral with links to oxygen atoms of the zeolite framework. Similar phenomena have been reported for ALD-Al of FAU [41, 53] and OKO [37] zeolites in literature.

Solid state ${ }^{27} \mathrm{Al}$ MAS NMR was employed to investigate the local bonding environment in the ALD-Si and ALD-Al modified PMFI and PMWW zeolite catalysts (Figure 3). In Si-PMFI and Si-PMWW samples, ${ }^{27} \mathrm{Al}$ MAS NMR signals were observed at $55 \mathrm{ppm}$ and $0 \mathrm{ppm}$, which can be ascribed to tetrahedral framework $\mathrm{Al}\left(\mathrm{Al}_{\mathrm{T}}\right)$ and octahedral extra framework $\mathrm{Al}\left(\mathrm{Al}_{\mathrm{O}}\right)$, respectively $[8,54-56]$. The ${ }^{27}$ Al MAS NMR spectra of Si-PMFI and Si-PMWW are consistent with their parent counterparts, PMFI and PMWW zeolites [8].The ${ }^{27} \mathrm{Al}$ MAS NMR spectra ALD-Al modified PMFI and PMWW zeolites contain not only the $\mathrm{Al}_{\mathrm{T}}$ and $\mathrm{Al}_{\mathrm{O}}$ peaks, but also an additional peak centered at $30 \mathrm{ppm}$ (Figure 3). The appearance of the new peak at $\sim 30 \mathrm{ppm}$ in Al-PMWW and Al-PMFI can be assigned to distorted tetrahedral framework and pentacoordinated $\mathrm{Al}$ species that were introduced via ALD-Al process [41]. The inclusion of new types of acid sites in ALD-Al process indicated by ${ }^{27} \mathrm{Al}$ MAS NMR analysis is consistent with the composition and $N_{\text {total, } \mathrm{H}^{+}}$analyses discussed above.

The types of acid sites in ALD-modified PMFI and PMWW zeolites were further characterized using FTIR spectra of adsorbed pyridine (Figure 4). Pyridine bound to Lewis acid sites is associated with the characteristic absorption band at $1460 \mathrm{~cm}^{-1}$ and that bound to Brønsted acid sites is affiliated with the band at $1545 \mathrm{~cm}^{-1}$ in the FTIR spectra $[17,57,58]$. In Figure 4(A), the absorption band at $1545 \mathrm{~cm}^{-1}$ of PMWW is similar to that of Si-PMWW, but slightly smaller than Al-PMWW. On the contrary, the adsorption band at $1460 \mathrm{~cm}^{-1}$ broadens from PMWW to Si-PMWW and Al-PMWW. In addition, the absorption peak in this band splits into multiple peaks with irregular shapes. The non- or slight change in absorption band for 
Brønsted acid sites in Figure 4(A) indicates that ALD-Si did not obviously modify the properties of Brønsted acid sites in PMWW zeolite. The "inhomogeneous broadening" in the Lewis acid band indicates the formation of various types of Lewis acid sites in PMWW zeolite materials via the ALD-Si or ALD-Al process [37, 53]. Figure 4(B) shows the FTIR spectra of adsorbed pyridine on PMFI zeolite before and after ALD modifications. Similarly, the band associated with Brønsted acid sites does not change obviously, while the band affiliated with Lewis acid sites exhibits "inhomogeneous broadening" and "peak splitting". It should be noted that the peak intensity of Al-PMFI at $1545 \mathrm{~cm}^{-1}$ is much higher and more obvious than that of PMFI and SiPMFI, which suggests the presence of a higher number of Brønsted acid sites. This evidence is in consistence with the higher number of acid sites in Al-PMWW determined from DME titrations above.

\subsection{External acid sites in pillared zeolites after ALD modifications}

Our previous studies indicated that a comparable number of acid sites reside on the external surface of zeolite nanosheets in unit-cell thick 2D PMWW and PMFI zeolites, which can be accessed by organic base (DTBP) probe molecules [8, 28, 59]. ALD modifications preferentially deposit $\mathrm{Si}$ - or Al-species on the external surface or in mesopores of pillared zeolites. It is expected that such modifications will abruptly influence the surface acidity and accessibility of external acid sites to bulky molecules of the pillared zeolite catalysts. To determine the number of Brønsted acid sites on external surface or in mesopores $\left(N_{\mathrm{ext}, \mathrm{H}^{+}}\right)$, and the fraction of external acid sites $\left(\mathrm{f}_{\mathrm{ext}, \mathrm{H}+}=N_{\mathrm{ext}, \mathrm{H}^{+}} / N_{\text {total, } \mathrm{H}^{+}}\right)$in ALD modified PMFI and PMWW zeolites, methanol reaction to DME in the presence of DTBP organic base was carried out. The rate loss upon DTBP saturation of external acid sites reflects the degree of accessibility of acid 
sites to bulky DTBP molecules, and hence, the number and fraction of external acid sites can be evaluated [45].

Table 1 lists $N_{\text {ext, } \mathrm{H}^{+}}$and $\mathrm{f}_{\text {ext, }} \mathrm{H}^{+}$in PMWW and PMFI zeolites before and after ALD-Si and ALD-Al modifications. In Si-PMWW zeolite, $\mathrm{f}_{\mathrm{ext}, \mathrm{H}^{+}}$decreased to $45 \%$ (was $67 \%$ in PMWW), reflecting $1.12 \times 10^{-4} \mathrm{~mol} \mathrm{H}^{+} \mathrm{g}^{-1}$ diminishment of external acid site $\left(N_{\mathrm{ext}, \mathrm{H}^{+}}\right)$after ALD-Si process. From DME titration data, the decrease in total number of acid sites $\left(N_{\left.\text {total, } \mathrm{H}^{+}\right)}\right.$ was $0.91 \times 10^{-4} \mathrm{~mol} \mathrm{H}^{+} \mathrm{g}^{-1}$, quite close to the number of dismissing external acid sites. In SiPMFI zeolite, $N_{\text {ext, } \mathrm{H}^{+}}$is reduced by $0.35 \times 10^{-4} \mathrm{~mol} \mathrm{H}^{+} \mathrm{g}^{-1}$ and $N_{\text {total, } \mathrm{H}+}$ is decreased by $0.59 \times 10^{-4}$ mol $\mathrm{H}^{+} \mathrm{g}^{-1}$. The similarity in reduction of $N_{\text {ext, } \mathrm{H}^{+}}$and $N_{\text {total, }} \mathrm{H}^{+}$in both Si-PMFI and Si-PMWW zeolites signifies that $\mathrm{Si}$-species is preferentially deposited on or near external acid sites of the catalysts, and thus influences acid site accessibility to DTPB titrants.

DME titration for the total number of acid sites in Al-PMWW sample shows that $N_{\text {total, } \mathrm{H}^{+}}$ is increased by $0.36 \times 10^{-4} \mathrm{~mol} \mathrm{H}^{+} \mathrm{g}^{-1}$ (Table 1). The DTBP titration in methanol reaction experiment illustrates that $N_{\text {ext, } \mathrm{H}^{+}}$is reduced by $0.93 \times 10^{-4} \mathrm{~mol} \mathrm{H}^{+} \mathrm{g}^{-1}$. The opposite trends, increase in total number of acid sites and reduction in external acid sites, in Al-PMWW zeolite indicates that acid site accessibility to bulky molecules is reduced. The material deposited on PMWW in ALD-Al is $\sim 3$ times more than that of ALD-Si, which might narrow down the micropore openings (blocking pore mouth acid sites) or mesopores existing between two zeolite nanosheets, and consequently, lead to incapability of external acid sites to access large molecules. For Al-PMFI zeolites, the increase in $N_{\text {total, } \mathrm{H}^{+}}$is $2.34 \times 10^{-4} \mathrm{~mol} \mathrm{\textrm {H } ^ { + }} \mathrm{g}^{-1}$, and $N_{\text {ext, } \mathrm{H}^{+}}$is also enhanced by $0.25 \times 10^{-4} \mathrm{~mol} \mathrm{H}^{+} \mathrm{g}^{-1}$, compared to those in PMFI zeolite (Table 1). The increase in $N_{\text {ext, } \mathrm{H}^{+}}$reflects that more Brønsted acid sites generated on the external surface of the PMFI zeolite, similar to the inclusion of acidity into siliceous zeolites reported previously [37]. The 
decrease in $\mathrm{f}_{\text {ext, }} \mathrm{H}^{+}$in Al-PMFI hints that accessibility of acid sites to bulky molecules is also reduced. The overall analysis shows that ALD is a tool that can insert acid sites and tune their distribution and accessibility to reactant molecules in 2D zeolite materials that have unit-cell thick nanosheets and high fractions of external surfaces.

3.5 Catalytic tests in acid catalyzed reactions

3.5.1 Ethanol dehydration reaction. Ethanol dehydration to diethyl ether (DEE) was used as a probe reaction to evaluate the intrinsic activity of PMFI and PMWW zeolites after ALD-Al and ALD-Si modifications. Under strict kinetic control, the transport artifacts on the kinetic data in ethanol dehydration reaction are expected to be eliminated, and thus catalyst activity should be directly related to the intrinsic behaviors of Brønsted acid sites in the zeolite catalysts $[8,60,61]$. In our tested conditions, DEE was the only product formed over the PMFIand PMWW zeolites and their derived structures after ALD modifications, indicating that ethanol dehydration reaction occurred through a bimolecular pathway, consistent with reports on DEE formation on medium- or large-pore zeolites $[60,61]$. These results indicate that ALD-Si or ALD-Al treatments of PMFI and PMWW zeolites did not create new type of pore topology or significantly reduce the environment of active acidic hydroxyl groups to small pores, which lead to formation of ethylene product in ethanol dehydration reactions.

Figure 5 shows the Arrhenius plots (the natural logarithm of regressed rate constants versus the inverse temperature) of ethanol dehydration rates over PMWW and PMFI zeolite catalysts before and after ALD modifications, respectively. The plots in both Figure 5(A) and (B) are parallel to each other, which indicates that all the studied zeolite samples have similar activation energies for ethanol dehydration. Table 2 lists the activation energy $\left(\Delta \mathrm{E}_{\text {meas }}\right)$, entropies 
$\left(\Delta \mathrm{S}_{\text {meas }}\right)$, and rate constants at $383 \mathrm{~K}$ ( $\left.\mathrm{k}_{\text {meas }}\right)$ for DEE formation over these six pillared zeolite samples. The site time yield of DEE differs among the zeolites by up to a factor of 1.2. Activation energies (90-99 $\mathrm{kJ} \mathrm{mol}^{-1}$ ) and entropies (within a range of -90 to $-67 \mathrm{~J} \mathrm{~mol}^{-1} \mathrm{~K}^{-1}$ ) are comparable. These results imply that Brønsted acid sites in pillared 2D zeolite materials possessing Al- or Si-species incorporated by ALD processes have similar catalytic activities compared to the parent pillared 2D PMWW and PMFI zeolites when measured under strict kinetic control conditions.

3.5.2 Alkylation of benzyl alcohol in mesitylene. While ethanol dehydration reaction measures the intrinsic activity of the catalysts, alkylation of benzyl alcohol in mesitylene depends on the accessibility of the bulky molecules to the acid sites in zeolite catalysts. Here, we compared the catalytic performance of external surfaces of PMWW and PMFI zeolites after ALD modifications using the liquid phase parallel catalytic conversions of benzyl alcohol in mesitylene (etherification to dibenzyl ether and alkylation to 1,3,5-trimethyl-2-benzylbenzene) as probe reactions. The apparent rate constants of the parallel alkylation and etherification reactions were evaluated at $348 \mathrm{~K}$, with less than $10 \%$ conversion of benzyl alcohol, under rigorous agitation, and in excess amount of mesitylene (molar ratio of mesitylene to benzyl alcohol $=45: 1$ ) to eliminate the effect of catalyst deactivation, external mass transfer limitations, and reaction that converts dibenzyl ether to 1,3,5-trimethyl-2-benzylbenzene [28, 59].

Previous studies indicated that the parallel reactions occur exclusively on the external surface of MWW catalysts with alkylation being favored over etherification reaction [28, 59]. By applying pseudo-first order reaction model on the reaction data, the external alkylation and etherification rate constants ( $k_{\text {alk,ext }}$ and $\left.k_{\text {eth,ext }}\right)$, respectively, can be readily analyzed. The model 
for the alkylation reaction is: $\ln \frac{C_{\mathrm{A}}^{0}}{C_{\mathrm{A}}}=k_{\mathrm{alk}, \mathrm{ext}} N_{\text {ext, } \mathrm{H}^{+}}(1+\alpha) t$, where $C_{A}^{0}$ is the initial benzyl alcohol concentration in solution $\left(\mathrm{mol} \mathrm{L}^{-1}\right), C_{A}$ is benzyl alcohol concentration in solution $\left(\mathrm{mol} \mathrm{L}^{-1}\right)$, $N_{\text {ext }, \mathrm{H}+}\left(\mathrm{mol} \mathrm{H}^{+}\right)$is the total moles of external Brønsted acid sites of the catalyst present in the batch reactor (Table 2), $\alpha$ is the product selectivity $\left(\alpha=2 \mathrm{C}_{\mathrm{E}} / \mathrm{C}_{\mathrm{C}}, \mathrm{C}_{\mathrm{E}}\right.$ and $\mathrm{C}_{\mathrm{C}}$ are the concentrations of dibenzyl ether and 1,3,5-trimethyl-2-benzylbenzene in solution (mol L ${ }^{-1}$ ), respectively), and $t$ is the reaction time (s), respectively, and the constant of external acid sites $\left(\mathrm{k}_{\mathrm{alk}, \mathrm{ext}}\left(\mathrm{s}^{-1}\left[\mathrm{~mol} \mathrm{H}^{+}\right]^{-1}\right)\right.$ can be solved using this model. Similarly, the model for etherification reaction on PMWW-type zeolites can be derived as: $\ln \frac{C_{\mathrm{A}}^{0}}{C_{\mathrm{A}}}=k_{\text {eth,ext }} N_{\text {ext, } \mathrm{H}^{+}}\left(\frac{1+\alpha}{\alpha}\right) t$, in which $\mathrm{k}_{\text {eth,ext }}\left(\mathrm{s}^{-1}\left[\mathrm{~mol} \mathrm{H}^{+}\right]^{-1}\right)$ is the rate constant. The selectivity between the parallel etherification and alkylation reactions, defined as $k_{\text {eth,ext }} / k_{\text {alk,ext }}$ across PMWW, Si-PMWW and Al-PMWW zeolites can be compared.

Figure 6(A)-(B) shows the reaction rate constants and selectivity of the parallel etherification and alkylation reactions over PMWW, Al-PMWW and Si-PMWW catalysts. The alkylation and etherification rate constants of PMWW zeolite are lower and higher, respectively, in comparison with the corresponding ALD-Si and ALD-Al modified Si-PMWW and AlPMWW zeolites (Figure 6(A)). Although ALD-Al introduced new types of acid sites on the PMWW zeolite, it did not enable efficient catalysis, which might be due to weak acid strength as evidenced by FTIR spectra of adsorbed pyridine in Figure 3(A). The selectivity towards the parallel reactions, shown in Figure 6(B), indicates that the alkylation reaction was slightly favored over the Si-PMWW while the etherification reaction was favored over the Al-PMWW in 
comparison with PMWW zeolite. These studies indicate that the activity and selectivity of external acid sites in 2D pillared zeolites can be tuned by ALD modifications.

The studies on parallel etherification and alkylation reactions over PMFI-type zeolites show that alkylation reaction only corresponds to external acid sites (similar to PMWW-type zeolites) while etherification reaction contains two contributions: one from external acid sites and the other from reaction inside the micropores (internal) [28, 59]. External alkylation rate constant can be readily analyzed using pseudo-first order reaction model discussed above to provide an understanding of catalytic behavior of external acid sites in PMFI, Si-PMFI and AlPMFI zeolites. Analysis of external etherification reaction rate constants over PMFI-type zeolites needs tremendous model development and verifications [28, 59]. Here, we simply used the equation, $\ln \frac{C_{\mathrm{A}}^{0}}{C_{\mathrm{A}}}=k_{\text {eth,total }} N_{\text {total, } \mathrm{H}+}\left(\frac{1+\alpha}{\alpha}\right) t$, to evaluate the etherification rate constant of the entire catalyst particle $\left(k_{\text {eth,total }}\left(\mathrm{s}^{-1}\left[\mathrm{~mol} \mathrm{H}^{+}\right]^{-1}\right)\right)$ and selectivity $\left(k_{\text {eth,total }} / k_{\text {alk,ext }}\right)$ of the parallel reactions over ALD modified PMFI zeolite catalysts. Figure $6(\mathrm{C})$ and (D) show similar trends in changing of activity and selectivity in PMFI-based catalysts to those of PMWW-based zeolites, further confirming that ALD can be an effective tool in tuning surface catalytic properties of the unitcell thick 2D zeolite catalysts.

3.5.3 Direct methane aromatization reaction. In DMA reactions, active sites on external surfaces of zeolite catalysts are easily accessed by reactants and are not protected against undesired side reactions by the shape-selective environment within zeolite channels, which causes coke and large hydrocarbons formation and leads to fast catalyst deactivation [62-65]. Studies have explored surface silanation method to deactivate external surface acid sites of zeolite catalysts [64-66], which were realized by the selective deposition of Si-species using 
large organosilane molecules that cannot enter zeolite channels. An enhancement in product formation rates and catalyst durability in DMA reactions has been observed over Mo/MFI zeolite catalysts after silanation treatments. Given the capability of selective controlling surface composition and acidity of $2 \mathrm{D}$ pillared zeolites by ALD processes, we modified the PMFI with ALD-Si process to passivate the surface active sites and tested its implications on the catalytic activity and selectivity of the Mo/Si-PMFI catalysts in DMA reactions.

Figure 7(A) shows the formation rate of aromatic products (a sum of benzene, toluene and naphthalene) over the $2 \mathrm{wt} \% \mathrm{Mo} / \mathrm{Si}$-PMFI catalyst, in which Si-PMFI were prepared after two and five ALD-Si cycles, respectively. For comparison purpose, DMA reactions over the Mo/PMFI zeolite were also studied, and the data were included in Figure 7(A). The rate of aromatic product formation in DMA reactions increased and then decreased after ALD-Si modification of PMFI zeolite for two and five cycles. The molecular size of Si-species precursor, TDMAS, is larger than the 10-MR micropores of PMFI zeolite, and thus the external surface active sites were selectively passivated in ALD-Si process. The removal of external acid sites of PMFI by ALD-Si successfully mitigated the anchoring of $\mathrm{MoO} x$ precursors and $\mathrm{MoC} x$ active species on external surfaces. This explains the reason for the catalytic activity improvement in Mo/Si-PMFI compared to Mo/MFI catalyst. With five ALD-Si cycles, a thicker film of Sispecies might form on the external surface of PMFI zeolite, which blocked the entrance of reactant into or exit of product out of the zeolite micropores. A reduction in catalytic activity in DMA reactions is therefore observed. Figure 7(B) shows the product selectivities in the Mo/PMFI and Mo/Si-PMFI catalysts. After two and five cycles of ALD-Si modification, the 2 wt $\% \mathrm{Mo} / \mathrm{Si}$-PMFI catalyst showed a lower selectivity to benzene and a higher selectivity to naphthalene products. The selectivity towards heavier naphthalene product in DMA reactions 
over Mo/Si-PMFI catalyst might result from longer transport pathways of reaction species in $\mathrm{Si}$ PMFI compared to PMFI zeolite. The ALD-Si process may partially block the 10-MR aperture of PMFI zeolite, and thus the residence time of reaction intermediate in micropores is prolonged. As a result, the product grows into heavier naphthalene instead of lighter benzene. The DMA reaction results demonstrate that $\mathrm{ALD}$-process improves catalytic activity and tunes the product selectivity of Mo/PMFI catalyst by the selective elimination of active sites from external surfaces of PMFI zeolite surfaces.

\section{Conclusions}

The external surface composition and acidity of PMWW and PMFI, a type of pillared zeolites comprised of unit-cell thick zeolitic nanosheets with micropore within each layer and mesopore between zeolitic layers, were modified by ALD-Si and ALD-Al, respectively. The ALD modifications kept micropore almost intact, but considerably decreased mesopore volume in both zeolite materials. The ALD-Si moderately decreased the external surface acidity, while ALD-Al increased the surface acidity and diversified the types of acid sites. The composition and acidity of $2 \mathrm{D}$ pillared zeolites were spatially modulated by ALD processes. The implications of the ALD modifications of PMWW and PMFI zeolites on catalytic reactions were tested using ethanol dehydration under kinetically controlled condition, alkylation of benzyl alcohol in mesitylene in liquid phase condition, and DMA reactions. Both ALD-Al and ALD-Si operations did not influence the intrinsic catalytic behaviors Brønsted of acid sites in PMWW and PMFI zeolites, but they tuned the catalytic selectivity of external acid sites in alkylation of benzyl alcohol with mesitylene reactions. The elimination of external surface active sites by ALD-Si of PMFI zeolite improved Mo/Si-PMFI catalyst activity and tuned the product selectivity. The 
present study exemplified for the first time that the external composition and acidity in 2D unitcell thick zeolites were tailored by ALD modifications to impact their activity and selectivity in catalytic reactions at different levels.

\section{Acknowledgements}

The authors gratefully acknowledge financial support from the ACS-Petroleum Research Fund (ACS-PRF, 52089-DNI5) and National Science Foundation (NSF-CBET 1264599 and 1351384). We acknowledge the support of Maryland NanoCenter and its NispLab. The NispLab is supported in part by the NSF as a MRSEC Shared Experimental Facility. Yiqing Wu thanks for the Hulka Energy Research Fellowship from University of Maryland Energy Research Center (UMERC) to support his research.

\section{References:}

[1] F.J. Liu, T. Willhammar, L. Wang, L.F. Zhu, Q. Sun, X.J. Meng, W. Carrillo-Cabrera, X.D. Zou, F.S. Xiao, J. Am. Chem. Soc., 134 (2012) 4557.

[2] K. Kim, R. Ryoo, H.D. Jang, M. Choi, J. Catal., 288 (2012) 115.

[3] W. Park, D. Yu, K. Na, K.E. Jelfs, B. Slater, Y. Sakamoto, R. Ryoo, Chem. Mater., 23 (2011) 5131.

[4] C.S. Cundy, P.A. Cox, Chem. Rev., 103 (2003) 663.

[5] M.E. Davis, Nature, 417 (2002) 813.

[6] J. Perez-Ramirez, C.H. Christensen, K. Egeblad, C.H. Christensen, J.C. Groen, Chem. Soc. Rev., 37 (2008) 2530.

[7] A. Corma, Chem. Rev., 97 (1997) 2373.

[8] D.X. Liu, A. Bhan, M. Tsapatsis, S. Al Hashimi, ACS Catal., 1 (2011) 7.

[9] W.J. Roth, P. Nachtigall, R.E. Morris, J. Cejka, Chem. Rev., 114 (2014) 4807.

[10] K. Moller, T. Bein, Chem. Soc. Rev., 42 (2013) 3689.

[11] M. Tsapatsis, W. Fan, Chemcatchem, 2 (2010) 246.

[12] T. Yokoi, T. Tatsumi, in: F.-S. Xiao, X. Meng (Eds.) Zeolites in Sustainable Chemistry, Springer Berlin Heidelberg, 2016, 77-100.

[13] B.Y. Liu, C. Wattanaprayoon, S.C. Oh, L. Emdadi, D.X. Liu, Chem. Mater., 27 (2015) 1479. 
[14] M. Mazur, P. Chlubna-Eliasova, W.J. Roth, J. Cejka, Catal. Today, 227 (2014) 37.

[15] W.J. Roth, C.T. Kresge, Micropor. Mesopor. Mat., 144 (2011) 158.

[16] A. Corma, U. Diaz, T. Garcia, G. Sastre, A. Velty, J. Am. Chem. Soc., 132 (2010) 15011.

[17] X.Y. Ouyang, S.J. Hwang, R.C. Runnebaum, D. Xie, Y.J. Wanglee, T. Rea, S.I. Zones, A. Katz, J. Am. Chem. Soc., 136 (2014) 1449.

[18] I. Ogino, E.A. Eilertsen, S.J. Hwang, T. Rea, D. Xie, X.Y. Ouyang, S.I. Zones, A. Katz, Chem. Mater., 25 (2013) 1502.

[19] K. Varoon, X.Y. Zhang, B. Elyassi, D.D. Brewer, M. Gettel, S. Kumar, J.A. Lee, S. Maheshwari, A. Mittal, C.Y. Sung, M. Cococcioni, L.F. Francis, A.V. McCormick, K.A. Mkhoyan, M. Tsapatsis, Science, 334 (2011) 72.

[20] I. Ogino, M.M. Nigra, S.J. Hwang, J.M. Ha, T. Rea, S.I. Zones, A. Katz, J. Am. Chem. Soc., 133 (2011) 3288.

[21] A. Corma, V. Fornes, S.B. Pergher, T.L.M. Maesen, J.G. Buglass, Nature, 396 (1998) 353.

[22] K. Na, M. Choi, W. Park, Y. Sakamoto, O. Terasaki, R. Ryoo, J. Am. Chem. Soc., 132 (2010) 4169.

[23] S. Maheshwari, E. Jordan, S. Kumar, F.S. Bates, R.L. Penn, D.F. Shantz, M. Tsapatsis, J. Am. Chem. Soc., 130 (2008) 1507.

[24] A. Zukal, M. Kubu, Dalton T., 43 (2014) 10558.

[25] T. Yokoi, S. Mizuno, H. Imai, T. Tatsumi, Dalton T., 43 (2014) 10584.

[26] O. Kikhtyanin, P. Chlubna, T. Jindrova, D. Kubicka, Dalton T., 43 (2014) 10628.

[27] U. Diaz, A. Corma, Dalton T., 43 (2014) 10292.

[28] X.Y. Zhang, D.X. Liu, D.D. Xu, S. Asahina, K.A. Cychosz, K.V. Agrawal, Y. Al Wahedi, A. Bhan, S. Al Hashimi, O. Terasaki, M. Thommes, M. Tsapatsis, Science, 336 (2012) 1684.

[29] M. Choi, K. Na, J. Kim, Y. Sakamoto, O. Terasaki, R. Ryoo, Nature, 461 (2009) 246.

[30] B.J. O'Neill, D.H.K. Jackson, J. Lee, C. Canlas, P.C. Stair, C.L. Marshall, J.W. Elam, T.F.

Kuech, J.A. Dumesic, G.W. Huber, ACS Catal., 5 (2015) 1804.

[31] J.L. Lu, J.W. Elam, P.C. Stair, Accounts Chem. Res., 46 (2013) 1806.

[32] S.L. Wegener, T.J. Marks, P.C. Stair, Accounts Chem. Res., 45 (2012) 206.

[33] I. Muylaert, J. Musschoot, K. Leus, J. Dendooven, C. Detavernier, P. Van der Voort, Eur. J. Inorg. Chem., (2012) 251.

[34] C. Marichy, M. Bechelany, N. Pinna, Adv. Mater., 24 (2012) 1017.

[35] J. Dendooven, B. Goris, K. Devloo-Casier, E. Levrau, E. Biermans, M.R. Baklanov, K.F. Ludwig, P. Van der Voort, S. Bals, C. Detavernier, Chem. Mater., 24 (2012) 1992.

[36] C. Detavernier, J. Dendooven, S.P. Sree, K.F. Ludwig, J.A. Martens, Chem. Soc. Rev., 40 (2011) 5242.

[37] E. Verheyen, S.P. Sree, K. Thomas, J. Dendooven, M. De Prins, G. Vanbutsele, E. Breynaert, J.P. Gilson, C.E.A. Kirschhock, C. Detavernier, J.A. Martens, Chem. Commun., 50 (2014) 4610.

[38] F. Wang, W.Y. Xiao, G.M. Xiao, Catal. Lett., 145 (2015) 860.

[39] F. Jiang, J.J. Huang, L. Niu, G.M. Xiao, Catal. Lett., 145 (2015) 947.

[40] H. Vuori, R.J. Silvennoinen, M. Lindblad, H. Osterholm, A.O.I. Krause, Catal. Lett., 131 (2009) 7.

[41] S.P. Sree, J. Dendooven, T.I. Koranyi, G. Vanbutsele, K. Houthoofd, D. Deduytsche, C. Detavernier, J.A. Martens, Catal. Sci. Technol., 1 (2011) 218.

[42] W.J.R. C.T. Kresge, K.G. Simmons, J.C. Vartuli, US Patent 5229341, 1993.

[43] W.J.R. C.T. Kresge, K.G. Simmons, J.C. Vartuli, WO Patent 92/011935, 1992. 
[44] J.O. Barth, A. Jentys, J. Kornatowski, J.A. Lercher, Chem. Mater., 16 (2004) 724.

[45] Y.Q. Wu, L. Emdadi, S.C. Oh, M. Sakbodin, D.X. Liu, J. Catal., 323 (2015) 100.

[46] Y. Wu, L. Emdadi, Z. Wang, W. Fan, D. Liu, Appl. Catal. Gen., 470 (2014) 344.

[47] P. Cheung, A. Bhan, G.J. Sunley, D.J. Law, E. Iglesia, J. Catal., 245 (2007) 110.

[48] P. Cheung, A. Bhan, G.J. Sunley, E. Iglesia, Angew. Chem. Int. Ed., 45 (2006) 1617.

[49] L. Emdadi, Y.Q. Wu, G.H. Zhu, C.C. Chang, W. Fan, T. Pham, R.F. Lobo, D.X. Liu, Chem. Mater., 26 (2014) 1345.

[50] Y.J. He, G.S. Nivarthy, F. Eder, K. Seshan, J.A. Lercher, Micropor. Mesopor. Mat., 25 (1998) 207.

[51] M.E. Leonowicz, J.A. Lawton, S.L. Lawton, M.K. Rubin, Science, 264 (1994) 1910.

[52] Y. He, T.C. Hoff, L. Emdadi, Y.Q. Wu, J. Bouraima, D.X. Liu, Catal. Sci. Technol., 4 (2014) 3064.

[53] B.D. Vandegehuchte, J.W. Thybaut, C. Detavernier, D. Deduytsche, J. Dendooven, J.A. Martens, S.P. Sree, T.I. Koranyi, G.B. Marin, J. Catal., 311 (2014) 433.

[54] D. Coster, A.L. Blumenfeld, J.J. Fripiat, J. Phys. Chem., 98 (1994) 6201.

[55] H. Lechert, Ber. Bunsenge. Physi. Chem., 92 (1988) 1059.

[56] J.P. Gilson, G.C. Edwards, A.W. Peters, K. Rajagopalan, R.F. Wormsbecher, T.G. Roberie, M.P. Shatlock, J. Chem. Soc. Chem. Comm., (1987) 91.

[57] C. Jo, R. Ryoo, N. Zilkova, D. Vitvarova, J. Cejka, Catal. Sci. Technol., 3 (2013) 2119.

[58] Z.T. Xue, T. Zhang, J.H. Ma, H.X. Miao, W.M. Fan, Y.Y. Zhang, R.F. Li, Micropor. Mesopor. Mat., 151 (2012) 271.

[59] D.X. Liu, X.Y. Zhang, A. Bhan, M. Tsapatsis, Micropor. Mesopor. Mat., 200 (2014) 287.

[60] H. Chiang, A. Bhan, J. Catal., 271 (2010) 251.

[61] C. Delaspozas, R. Lopezcordero, J.A. Gonzalezmorales, N. Travieso, R. Roquemalherbe, J. Mol. Catal., 83 (1993) 145.

[62] Y.B. Xu, Y. Song, Y. Suzuki, Z.G. Zhang, Catal. Sci. Technol., 3 (2013) 2769.

[63] V.I. Zaikovskii, A.V. Vostnerikov, V.F. Anufrienko, L.L. Korobitsyna, E.G. Kodenev, G.V.

Echevskii, N.T. Vasenin, S.P. Zhuravkov, E.V. Matus, Z.R. Ismagilov, V.N. Parmon, Kinet. Catal., 47 (2006) 389.

[64] S. Kikuchi, R. Kojima, H.T. Ma, J. Bai, M. Ichikawa, J. Catal., 242 (2006) 349.

[65] W.P. Ding, G.D. Meitzner, E. Iglesia, J. Catal., 206 (2002) 14.

[66] S.R. Zheng, H.R. Heydenrych, A. Jentys, J.A. Lercher, J. Phys. Chem. B, 106 (2002) 9552. 


\section{List of Tables:}

Table 1. Composition and acidity of PMWW and PMFI zeolites after ALD modifications.

\begin{tabular}{|c|c|c|c|c|c|}
\hline Zeolites & $\mathrm{Si} / \mathrm{Al}^{a}$ & $\mathrm{Si} / \mathrm{Al}^{b}$ & $\begin{array}{c}N_{\text {total, } \mathrm{H}}^{+c} \\
{\left[\mathrm{~mol} \mathrm{H}^{+} \mathrm{g}^{-1}\left(\mathrm{x} 10^{-4}\right)\right]}\end{array}$ & $\mathrm{f}_{\mathrm{ext}, \mathrm{H}}^{+}(\%)^{d}$ & $\begin{array}{c}N_{\text {ext,H }}^{+e} \\
{\left[\mathrm{~mol} \mathrm{H}^{+} \mathrm{g}^{-1}\left(\mathrm{x} 10^{-4}\right)\right]}\end{array}$ \\
\hline PMWW & 31 & 50 & 3.30 & 67 & 2.21 \\
\hline Si-PMWW & 33 & 59 & 2.39 & 45 & 1.08 \\
\hline Al-PMWW & 7 & 7 & 3.66 & 35 & 1.28 \\
\hline PMFI & 56 & 68 & 1.85 & 36 & 0.67 \\
\hline Si-PMFI & 57 & 84 & 1.26 & 25 & 0.32 \\
\hline Al-PMFI & 6 & 5 & 4.19 & 22 & 0.92 \\
\hline
\end{tabular}

Table 2. Rate constants ( $\left.\mathrm{k}_{\text {meas }}\right)$ of DEE production at $383 \mathrm{~K}$, measured activation energy ( $\mathrm{E}_{\text {meas }}$ ) and entropy $\left(\Delta \mathrm{S}_{\text {meas }}\right)$ of DEE synthesis over PMWW and PMFI zeolites before and after ALD-Si and ALD-Al modifications, respectively.

\begin{tabular}{lcccccc}
\hline Catalyst & PMWW & Si-PMWW & Al-PMWW & PMFI & Si-PMFI & Al-PMFI \\
\hline $\begin{array}{l}\mathrm{k}_{\text {meas }} \\
\left(10^{-5} \mathrm{~mol}\left[\mathrm{~mol} \mathrm{H}^{+}\right]^{-1} \mathrm{~s}^{-1}\right)\end{array}$ & 36.1 & 35.8 & 29.6 & 30.4 & 38.0 & 31.6 \\
\hline
\end{tabular}




\begin{tabular}{lllllll}
\hline $\begin{array}{l}\mathrm{E}_{\text {meas }}{ }^{-1} \\
\left(\mathrm{~kJ} \mathrm{~mol}^{-1}\right)\end{array}$ & 91.9 & 91.5 & 92.7 & 99.5 & 99.1 & 90.4 \\
\hline $\begin{array}{l}\Delta \mathrm{S}_{\text {meas }}{ }^{-1} \\
\left(\mathrm{~J} \mathrm{~mol}^{-1} \mathrm{~K}^{-1}\right)\end{array}$ & -84.8 & -85.6 & -84.7 & -67.1 & -66.8 & -90.0 \\
\hline${ }^{a}$ Errors are $\pm 3 \mathrm{~kJ} \mathrm{~mol}^{-1}{ }^{b}$ Errors are $\pm 4 \mathrm{~J} \mathrm{~mol}^{-1} \mathrm{~K}^{-1}$. & & &
\end{tabular}

\section{List of Figures:}
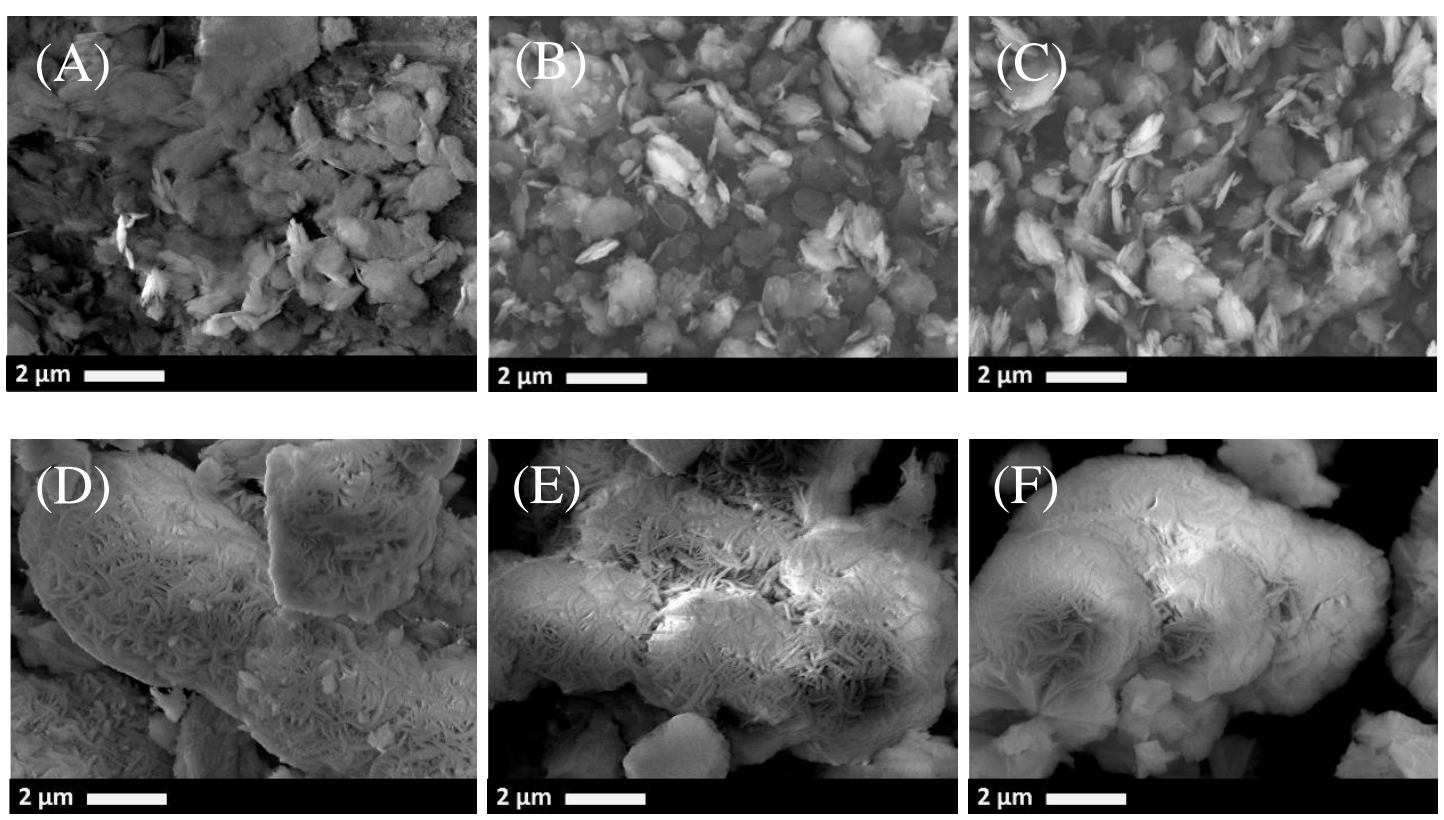

Figure 1. SEM images of PMWW (A), Si-PMWW (B), Al-PMWW (C), PMFI (D), Si-PMFI (E) and Al-PMFI (F), showing the morphology of unit-cell thick 2D pillared zeolites before and after ALD modifications. 

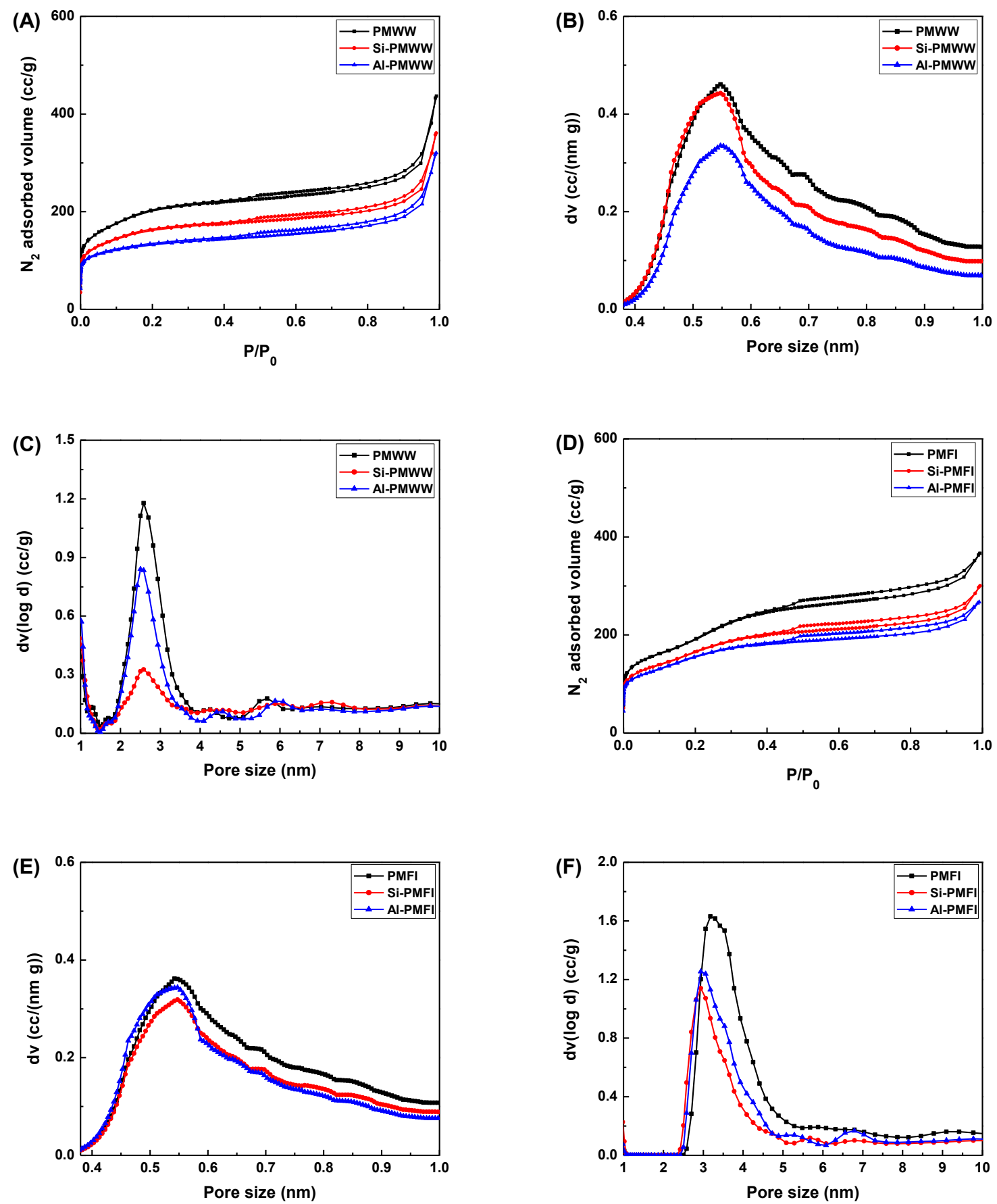

Figure 2. $\mathrm{N}_{2}$ adsorption-desorption isotherm ( $\mathrm{A}$ and $\mathrm{D}$ ), Horváth-Kawazoe (HK) micropore size distribution (B and E) and NLDFT mesopore size distribution (C and F) of PMWW and PMFI zeolites before and after ALD modifications. 


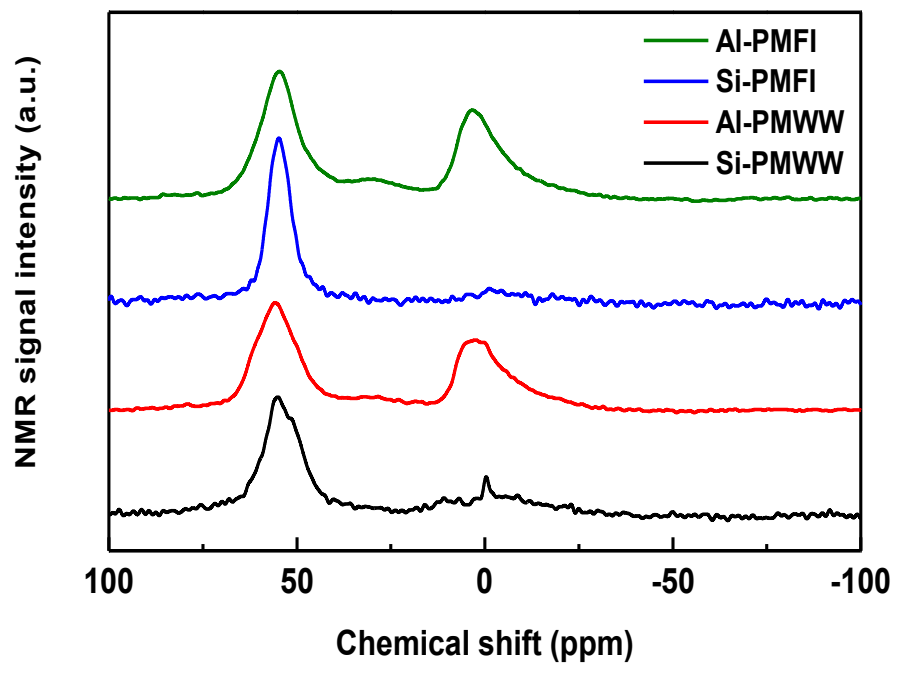

Figure 3. ${ }^{27} \mathrm{Al}$ MAS NMR spectra of Al-PMFI, Si-PMFI, Al-PMWW and Si-PMWW, respectively.
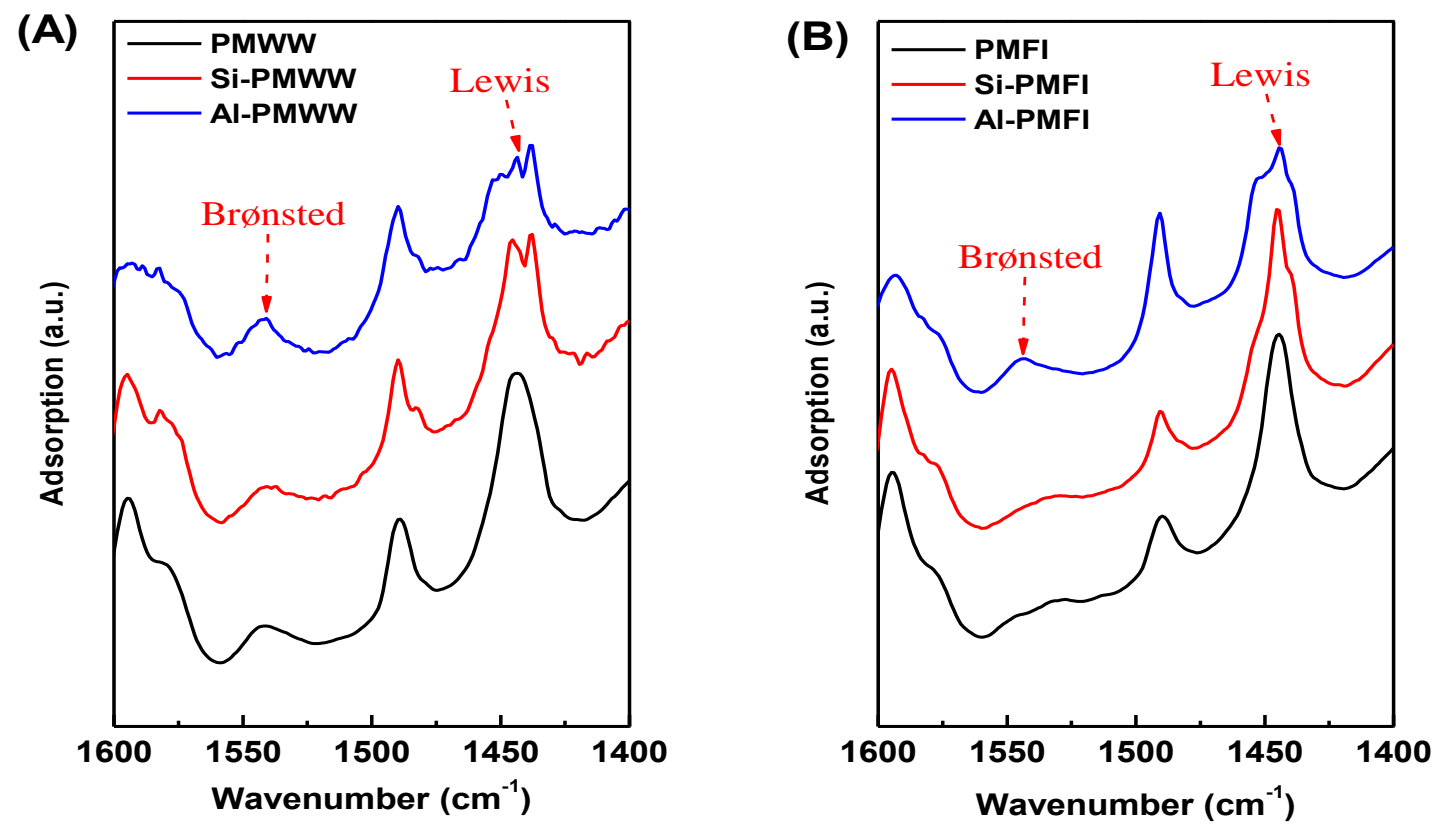
Figure 4. FTIR spectra of adsorbed pyridine of (A) PMWW and (B) PMFI zeolites before and after ALD modifications.
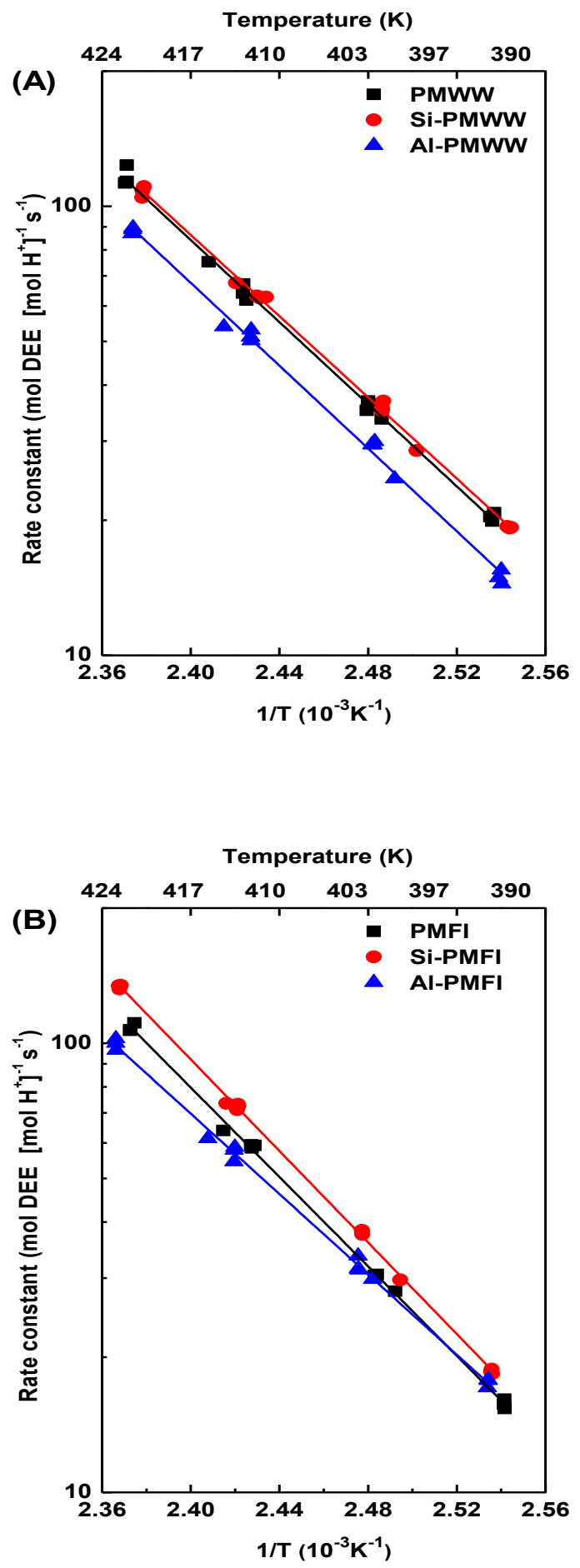
Figure 5. Measured rate constants of DEE production over PMWW (A) and PMFI (B) zeolite catalysts before and after ALD modifications.
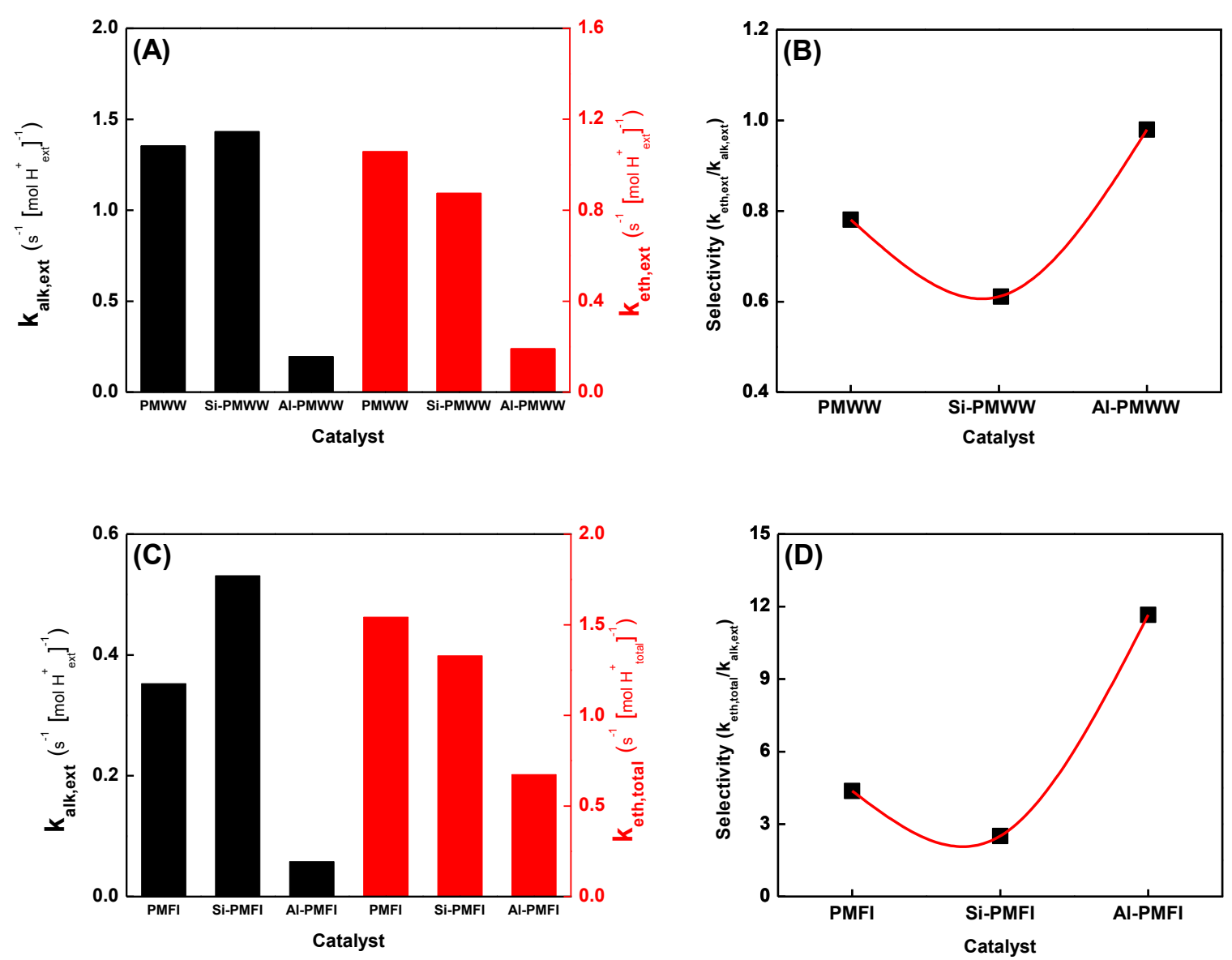

Figure 6. Catalytic conversion of benzyl alcohol in mesitylene over PMFI and PMWW zeolites before and after ALD modifications: (A) Alkylation and etherification reaction on external acid site of PMWW-based zeolite catalysts, (B) Selectivity for alkylation and etherification reactions on external acid site of PMWW-based zeolite catalysts, (C) Alkylation on external acid site and etherification reaction on entire acid site of PMFI-based zeolite catalysts, and (D) Selectivity for alkylation on external acid site and etherification reaction on entire acid site of PMFI-based zeolite catalysts. 

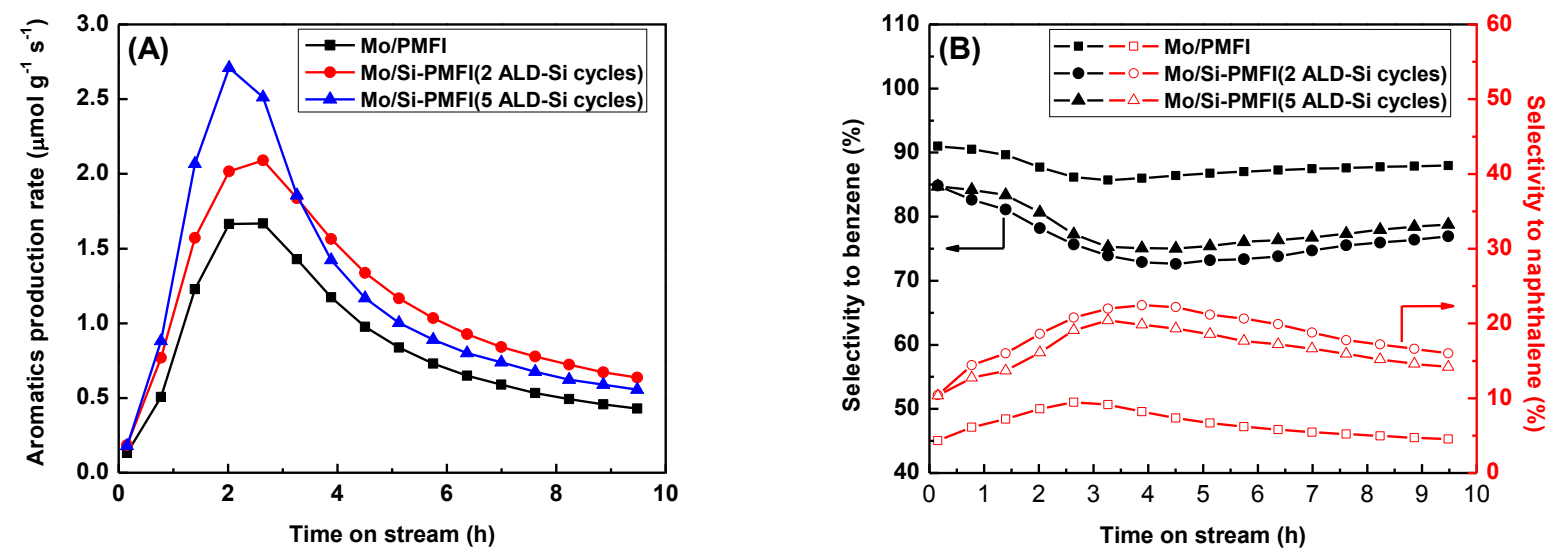

Figure 7. Aromatic product formation rate (A) and product selectivity (B) of DMA reactions as a function of time on steam on $2 \mathrm{wt} \% \mathrm{Mo} / \mathrm{PMFI}$ and $2 \mathrm{wt} \% \mathrm{Mo} / \mathrm{Si}-\mathrm{PMFI}$ catalysts, in which two and five ALD-Si cycles were applied to PMFI, respectively. 